\title{
Magnetic resonance imaging of the fetal brain
}

\author{
Lawrence MF Tee *, Elaine YL Kan, Joey CY Cheung, WC Leung
}

\section{A B S T R A C T}

Introduction: This review covers the recent literature on fetal brain magnetic resonance imaging, with emphasis on techniques, advances, common indications, and safety.

Methods: We conducted a search of MEDLINE for articles published after 2010. The search terms used were "(fetal OR foetal OR fetus OR foetus) AND (MR OR MRI OR [magnetic resonance]) AND (brain OR cerebral)". Consensus statements from major authorities were also included. As a result, 44 relevant articles were included and formed the basis of this review.

Results: One major challenge is fetal motion that is largely overcome by ultra-fast sequences. Currently, single-shot fast spin-echo T2-weighted imaging remains the mainstay for motion resistance and anatomical delineation. Recently, a snap-shot inversion recovery sequence has enabled robust T1weighted images to be obtained, which is previously a challenge for standard gradient-echo acquisitions. Fetal diffusion-weighted imaging, diffusion tensor imaging, and magnetic resonance spectroscopy are also being developed. With multiplanar capabilities, superior contrast resolution and field of view, magnetic resonance imaging does not have the

This article was published on $22 \mathrm{Apr}$ 2016 at www.hkmj.org. limitations of sonography, and can provide additional important information. Common indications include ventriculomegaly, callosum and posterior fossa abnormalities, and twin complications. There are safety concerns about magnetic resonance-induced heating and acoustic damage but current literature showed no conclusive evidence of deleterious fetal effects. The American College of Radiology guideline states that pregnant patients can be accepted to undergo magnetic resonance imaging at any stage of pregnancy if risk-benefit ratio to patients warrants that the study be performed.

Conclusions: Magnetic resonance imaging of the fetal brain is a safe and powerful adjunct to sonography in prenatal diagnosis. It can provide additional information that aids clinical management, prognostication, and counselling.

\section{Hong Kong Med J 2016;22:270-8}

DOI: $10.12809 / \mathrm{hkmj} 154678$

\author{
${ }^{1}$ LMF Tee *, FHKCR, FHKAM (Radiology) \\ ${ }^{1}$ EYL Kan, FHKCR, FHKAM (Radiology) \\ 1 JCY Cheung, MHIthSc (MRS) \\ ${ }^{2}$ WC Leung, MD, FRCOG \\ 1 Department of Diagnostic and Interventional Radiology \\ 2 Department of Obstetrics and Gynaecology \\ Kwong Wah Hospital, Yaumatei, Hong Kong \\ * Corresponding author: Imftee@gmail.com
}

\section{Introduction}

Fetal magnetic resonance (MR) imaging has been an invaluable adjunct to sonography in evaluation of the fetal brain since its introduction in the 1980s. In recent years, there has been an exponential growth in its clinical use, facilitated by technological advancements such as ultra-fast imaging sequences, diffusion-weighted imaging (DWI), and parallel imaging techniques. To date, sonography remains the mainstay modality in prenatal evaluation, owing to its low cost, abundant availability, and well-established literature support. Nonetheless, MR imaging has been shown to provide useful complementary information to sonography, ${ }^{1,2}$ and has a number of advantages over sonography, including superior contrast resolution, increased field of view (FOV), and the ability to image unhampered by an ossified calvarium, large maternal body habitus, or oligohydramnios. ${ }^{3-5}$ Currently, fetal MR imaging is most commonly used to confirm or characterise an abnormality that is suspected on sonography, or to screen fetuses at increased risk of neurodevelopmental disabilities.

In this article, we review the recent literature and developments in MR imaging of the fetal brain, with an emphasis on the safety, imaging techniques and protocols, and common clinical indications.

\section{Methods}

We performed a MEDLINE search for all the relevant scientific articles published in 2010 or later, using the keywords "(fetal OR foetal OR fetus OR foetus) AND (MR OR MRI OR [magnetic resonance]) AND (brain OR cerebral)". All papers published in English and on human subjects were included. This yielded a total of 331 articles. These were then evaluated for their content and relevance to this review article, with case reports being excluded. Ultimately, 40 articles were deemed relevant and used as the literature basis of this review. In addition, four consensus statements and clinical guidelines from major authorities, including the American College of Radiology (ACR), 
the International Commission on Non-Ionizing Radiation Protection (ICNIRP), the Health and Safety Executive (HSE), and the American Academy of Pediatrics, were included. Relevant or important citations in the articles were also reviewed. With reference to the data from these articles, we describe the imaging techniques and recent developments, common clinical indications, and safety issues of MR imaging of the fetal brain.

\section{Safety}

Fetal imaging is a relatively new MR application. While it is generally believed to be a safe and noninvasive procedure, ${ }^{6}$ safety concerns have been raised regarding the possible or theoretical adverse effects related to the radiofrequency (RF) field and acoustic exposure. ${ }^{7}$ A number of animal studies have been performed to assess the safety of MR imaging in pregnant animals and animal fetuses, but there is a lack of consensus regarding the actual risks, if any. ${ }^{7}$ In addition, these studies were performed under various conditions and MR protocols, making it difficult to directly extrapolate the results to human fetal MR examination. Overall, most studies have shown no deleterious effects of MR imaging on the developing fetus. ${ }^{4,7-9}$

\section{Radiofrequency-induced hyperthermia}

Radiofrequency-induced hyperthermia is a potential hazard in MR imaging. During an MR examination, RF energy is converted to heat via Faraday's law and is normally dissipated by blood flow. The amount of heat generated is a function of magnetic field strength, RF field, body size, tissue resistance, and scan time. Generally, pregnant women have a similar ability to maintain heat balance to non-pregnant women in a warm environment. Since the fetus does not possess the effective heat dissipation mechanisms of an adult, fetal temperature is dissipated via amniotic fluid and umbilical blood flow to the mother, and is thus coupled to maternal temperature, which is usually $0.5^{\circ} \mathrm{C}$ higher. Therefore, the fetus is considered to be more sensitive to hyperthermia. The 2004 ICNIRP report concludes that "Excessive heating is a potential teratogen; because of uncertainties in the RF dosimetry during pregnancy, it is recommended that exposure duration should be reduced to the minimum and that only the normal operation level is used", and that "It seems reasonable to assume that adverse developmental effects will be avoided with a margin of safety if the body temperature of pregnant women does not rise by more than $0.5^{\circ} \mathrm{C}$ and the temperature of the fetus is less than $38^{\circ} \mathrm{C}^{\prime 10}$

\section{Acoustic exposure}

A characteristic of the switching gradient fields is the production of acoustic noise. When the alternating

\section{使用磁共振成像替胎兒腦部進行檢測 \\ 鄭文輝、簡以靈、張中義、梁永昌}

引言：本文回顧磁共振成像在觀察胎兒腦部的應用的新近文獻，並集 中討論其技術、新發展、常見適應症和安全性。

方法：根據MEDLINE數據庫檢索2010年以後發表的文章。用於搜 索的關鍵詞是「胎兒」（fetal / foetal / fetus / foetus ) 和「磁共振」 ( MR / MRI / magnetic resonance ) 和 $\ulcorner$ 腦」（brain / cerebral）。 檢索範圍也包括來自各大機構的共同聲明。是次檢索結果共有 44 篇相 關文章。

結果：磁共振成像的超快序列可以解決因胎兒移動而對成像構成的影 響。目前, 單次激發快速自旋回波 T2加權成像仍是對抗運動偽影和 作結局定位的關鍵。快照反轉回復序列能產生強大的 $\mathrm{T} 1$ 加權像, 這是 過往標準梯度回波採集未必能達到的。胎擴散加權成像、彌散張量成 像和磁共振波譜的技術亦正在開發。磁共振成像有多向平面功能、高 對比度、高分辨率和大成像視野, 所以不再受到與超聲一樣的種種限 制, 並且可以提供額外的重要信息。常見的適應症包括腦室擴大、胼 胝體和後覤窩異常, 以及雙併發症。至於磁共振引起的發熱和噪音損 害, 目前的文獻並未有足夠證據顯示會對胎兒產生有害的影響。美國 放射學學會的聲明提出在權衡風險和效益後, 懷孕者可在妊娠的任何 階段接受磁共振成像。

結論：與超聲比較, 使用磁共振成像替胎兒腦部進行產前檢測是一種 安全及有用的方法。它能夠為臨床管理、病況預測和病人諮詢提供更 多信息。 low-frequency currents flow through the gradient coils, which are immersed in the high static magnetic field B0, forces are exerted on the gradient coils that move like a loudspeaker coil and generate sound waves. Exposure to excessive loud noises can result in a reduced sensitivity of the hair cells in the organ of Corti and cause a temporary shift in the threshold of hearing. The impact depends on the sound pressure level (measured in A-weighted decibel, $\mathrm{dB}[\mathrm{A}]$ ) and duration of exposure. A sufficient injurious acoustic exposure can result in a permanent hearing loss; 85 $\mathrm{dB}(\mathrm{A})$ is the threshold for permanent hearing loss following long-term exposure. Thus, the ICNIRP recommends that hearing protection should be provided to patients when sound levels exceed $80 \mathrm{~dB}(\mathrm{~A}) .{ }^{10}$ It is unclear how these guidelines can be applied to the fetus, in whom the cochlea is developing, and the external auditory canal and middle ear cavity are fluid-filled instead of air-filled. Therefore, concerns have been raised regarding possible effects of acoustic exposure during fetal MR on the developing auditory system of the fetus, especially in echo-planar imaging that is the loudest sequence in current clinical use.

In the literature reviews published by HSE and American Academy of Pediatrics, most published studies were limited by their methodology and study design, and no conclusive evidence of acoustic 
damage was shown. ${ }^{11,12}$ A 3-year follow-up study of children who underwent fetal MR imaging showed no adverse long-term effect on hearing, although this was limited by the relatively small sample size. ${ }^{7}$ Compared with adult patients, the exact effect of acoustic noise on the fetus is difficult to ascertain, because there are a number of variables that could alter the effect, for instance, maternal body size, volume of amniotic fluid, MR sequences used, and duration of scanning. In a study by Glover et al, ${ }^{13}$ the authors aimed to simulate the in-utero acoustic environment by inserting a microphone into the fluid-filled stomach of a volunteer, and found a $>30$ $\mathrm{dB}$ attenuation in sound intensity. This provides some reassurance that a level close to the instantaneous damage threshold (120 $\mathrm{dB}[\mathrm{A}])$ could be reduced to an acceptable level $(<90 \mathrm{~dB}[\mathrm{~A}])$. Overall, the data from the current literature provide reassuring clinical and experimental evidence that suggests no significant risk of acoustic injury to the fetus during prenatal MR imaging.

\section{Gadolinium contrast medium}

Gadolinium is a pregnancy class $C$ drug, and currently there are no documented indications for use of gadolinium contrast in fetal MR imaging. ${ }^{9}$ Gadolinium can pass through the placental barrier and enter the fetal circulation, with unknown and potentially harmful effects on the fetus. In animal studies, large doses of MR imaging gadolinium-based contrast agents have been shown to be associated with intrauterine death and congenital anomalies. ${ }^{7}$ The 2013 ACR guidance document on MR safe practices states that "MR contrast agents should not be routinely provided to pregnant patients". ${ }^{14}$

\section{Summary}

The 2013 ACR guidance document on MR safe practices states that "Pregnant patients can be accepted to undergo MR scans at any stage of pregnancy if, in the determination of a level $2 \mathrm{MR}$ personnel-designated attending radiologist, the risk-benefit ratio to the patient warrants that the study be performed". ${ }^{14}$ While present data have not conclusively documented any deleterious effects of MR imaging exposure on the developing fetus, as a precaution, it is generally recommended to wait until the second trimester onwards before performing fetal MR imaging. This has the additional benefit of minimising the technical challenges due to the small size and excessive motion of younger fetuses.

\section{Techniques and protocols}

\section{Coil selection}

Fetal MR imaging is typically performed on a 1.5-tesla magnet. Currently, either multi-channel phasedarray coils or cardiac surface coils are employed for fetal brain MR, with the coils placed directly over the fetal head. ${ }^{6}$ These coils generally lack mechanical design and flexibility, as maternal size is highly variable and is also dependent on the gestational age of the fetus. With the advent of parallel imaging techniques, the numbers of elements in phasedarray coils have continuously increased to achieve a higher signal-to-noise ratio (SNR) and shorter scan times. More recently, the invention of the digital coil platform combined with multiple coil elements has further enhanced SNR beyond the capabilities of the adult eight-channel torso coil routinely used in fetal imaging.

\section{Patient positioning}

Patients are placed in a semi-decubitus position, rotating about $45^{\circ}$ to the left side to avoid compression of the inferior vena cava and supported with foam pads to maximise comfort so as to minimise maternal and fetal movement. No maternal or fetal sedation is required.

\section{Scout views}

Scout images are obtained to localise the fetus and also serve as a general survey of the feto-placental unit. An initial localiser is obtained in three orthogonal planes with respect to the mother, using 6- to $8-\mathrm{mm}$ thick slices with a 1 - to $2-\mathrm{mm}$ gap and a large FOV. The localiser is used to visualise the position of the fetus and determine fetal sidedness, as well as to ensure that the coil is centred over the fetal brain. At our centre, we use a gradientecho scout localiser with a large FOV of $450 \mathrm{~mm}$ to cover the abdomen and pelvis of the mother, with a resolution of $1.76 \times 1.76 \times 10 \mathrm{~mm}^{3}$, and 20 slices in three orthogonal planes. A repeat localiser is then placed in the three orthogonal planes of the fetal brain. During the examination, each sequence also serves as a scout for the next. Due to fetal movement throughout the scanning process, repeating of scout localisers and repositioning of the coil are sometimes necessary. Therefore efforts should be made to keep the scanning time short.

\section{Sequences}

High image quality and resolution are crucial to accurate diagnosis; at the same time, a relatively short scan time is required to minimise the effects of fetal movement. Therefore, the choice of technical parameters should strike a balance between image quality and scan time (Table).

Single-shot fast spin-echo (SSFSE) T2weighted imaging is regarded as the mainstay of fetal MRI. ${ }^{3,5,6,8,9,15-19}$ It provides excellent delineation of cerebral anatomy and requires a total acquisition time of $<1$ second per image. On our $1.5 \mathrm{~T} \mathrm{MR}$ scanner system (Achieva XR 1.5T; Philips Medical Systems, Best, Netherlands), SSFSE T2-weighted 
TABLE. Typical sequence parameters for fetal brain MR imaging at our centre (Achieva XR I.5T; Philips Medical Systems, Best, Netherlands)

\begin{tabular}{|c|c|c|c|c|c|c|c|c|c|c|c|c|c|}
\hline & Plane & FOV (mm) & $\begin{array}{c}\text { Thickness/ } \\
\text { gap (mm) }\end{array}$ & Matrix & $\begin{array}{l}\text { Resolution } \\
\text { (mm) }\end{array}$ & $\begin{array}{c}\text { TR } \\
(\mathrm{ms})\end{array}$ & $\begin{array}{c}\text { TE } \\
\text { (ms) }\end{array}$ & $\begin{array}{c}\mathrm{TI} \\
(\mathrm{ms})\end{array}$ & ETL & $\begin{array}{l}\text { Flip } \\
\text { angle }\end{array}$ & $\begin{array}{l}\text { No. of } \\
\text { slices }\end{array}$ & $\begin{array}{c}\text { Time } \\
\text { (s) }\end{array}$ & NEX \\
\hline $\begin{array}{l}\text { Localisers } \\
\text { (mother) }\end{array}$ & $\begin{array}{l}\text { Axial, coronal, sagittal } \\
\text { (wrt mother) }\end{array}$ & $450 \times 450 \times 130$ & $6-8 / 1-2$ & $256 \times 256$ & $1.76 \times 1.76 \times 10$ & 2.9 & 1.43 & - & - & 60 & 20 & 14.8 & 1 \\
\hline $\begin{array}{l}\text { Localisers } \\
\text { (fetal brain) }\end{array}$ & $\begin{array}{l}\text { Axial, coronal, sagittal } \\
\text { (wrt fetal brain) }\end{array}$ & $380 \times 380 \times 88$ & $3.0 / 0.3$ & $480 \times 480$ & $0.79 \times 0.79 \times 3.2$ & 4.1 & 2.1 & - & - & 65 & 25 & 28.5 & 1 \\
\hline $\begin{array}{l}\text { T2 SSh TSE } \\
\text { DRIVE }\end{array}$ & Axial, coronal, sagittal & $380 \times 250 \times 80$ & $3.0 / 0.3$ & $480 \times 480$ & $0.79 \times 0.79 \times 3.2$ & 1450 & 80 & - & 227 & 90 & 25 & 34.8 & 2 \\
\hline T1 SSh TFE & Axial, coronal, sagittal & $380 \times 250 \times 88$ & $3.0 / 0.3$ & $384 \times 384$ & $0.99 \times 0.98 \times 3.2$ & 9.2 & 4.6 & - & 178 & 15 & 25 & 168 & 3 \\
\hline SNAPIR & Axial, coronal, sagittal & $230 \times 230 \times 100$ & $4 / 0$ & $288 \times 288$ & $0.8 \times 0.8 \times 4$ & 20000 & 8.6 & 400 & 230 & - & 25 & 200 & 1 \\
\hline DWI & Axial & $300 \times 300 \times 80$ & $5 / 2$ & $192 \times 192$ & $1 \times 1 \times 1$ & 2500 & 80 & $b=600$ & EPI & 90 & 10 & 18 & 1 \\
\hline
\end{tabular}

Abbreviations: DWI = diffusion-weighted imaging; EPI = echo-planar imaging; $E T L=$ echo train length; FOV = field of view; $M R$ = magnetic resonance; NEX = number of excitations; SNAPIR = snap-shot inversion recovery; SSh TFE = single-shot turbo field-echo; SSh TSE = single-shot turbo spin-echo; $\mathrm{TE}=$ echo time; $\mathrm{TI}=$ inversion time; $\mathrm{TR}=$ repetition time; wrt $=$ with respect to

sequences in the axial, coronal, and sagittal plane of the fetal brain are acquired, with 25 slices in 35 seconds, resolution at $0.79 \times 0.79 \times 3.2 \mathrm{~mm}, 0.3$ $\mathrm{mm}$ gap, long echo train length (ETL) of 227 and relatively short repetition time (TR) of $1450 \mathrm{~ms}$, and use of the driven equilibrium pulse to enhance T2 contrast with a shorter TR.

Single-shot multiplanar T1-weighted turbo field-echo sequences are acquired to detect haemorrhage, fat, or calcification. . $35,6,8,9$ Snap-shot inversion recovery, a dedicated optimised inversionrecovery-prepared SSFSE T1-weighted sequence, offers detailed delineation of normal fetal brain anatomy and myelination near term. ${ }^{20}$ At our centre, we use an inversion time of about $400 \mathrm{~ms}$, resolution at $0.8 \times 0.8 \times 4 \mathrm{~mm}, 25$ slices in 3 minutes 20 seconds, and single-shot mode with ETL of 230 .

Diffusion-weighted imaging provides quantitative information about water motion and tissue microstructure, and can be used to identify focal areas of injury and delineate subtle anatomical structures and maturational changes. $3,8,15,21,22$ Other advanced techniques are also being developed and may provide functional and physiological information, including fetal MR spectroscopy, diffusion tensor imaging, and functional imaging, ${ }^{7,823-30}$ although their development is still at an early stage.

\section{Indications}

Fetal MR imaging is often performed to further evaluate a suspected abnormality detected on sonography. By providing additional information on the suspected abnormality and detecting associated cerebral abnormalities that are otherwise occult on sonography, fetal MR imaging can guide antenatal and perinatal management, as well as assist in the counselling of current and future pregnancies. ${ }^{5,31-34}$ It has also been shown to demonstrate a high diagnostic accuracy when compared with repeat or postnatal MR imaging. ${ }^{35,36}$ The most common clinical indications for fetal MR imaging will be discussed below.

\section{Ventriculomegaly}

Ventriculomegaly is one of the most common clinical indications for fetal MR imaging, mainly to detect other associated abnormalities that are occult on sonography. Ventriculomegaly is defined as atrial width of $>10 \mathrm{~mm}$ on sonography, measured in the axial plane, at the level of the frontal horns and cavum septi pellucidi, at the level of the glomus of the choroid plexus, and perpendicular to the long axis of the lateral ventricle. ${ }^{3,5,6}$

Ventriculomegaly is a relatively common abnormality detected on prenatal sonography. It is a heterogeneous disease with various aetiologies that can be classified into developmental, destructive, and obstructive pathologies. An important prognostic factor is whether the ventriculomegaly is isolated, or with additional associated abnormalities. ${ }^{26}$ Studies have shown that up to $80 \%$ of fetuses with ventriculomegaly have other associated central nervous system (CNS) abnormalities, and is associated with poor postnatal neurological and developmental outcomes ${ }^{3,37}$ (Fig 1). These include agenesis of the corpus callosum, cortical malformation, periventricular nodular heterotopia, and destructive processes such as periventricular leukomalacia, porencephaly, and intra-ventricular and subependymal haemorrhage. ${ }^{3,6,37}$ On the other hand, the majority of fetuses with isolated mild ventriculomegaly show normal neurodevelopmental outcomes. Fetal MR imaging has been shown to have a high sensitivity and specificity for these brain abnormalities ${ }^{18}$ that may be occult and unidentified on sonography. ${ }^{25,34,38-40}$ These data highlight the role of fetal MR imaging in the prognostication of ventriculomegaly, and have significant implications 


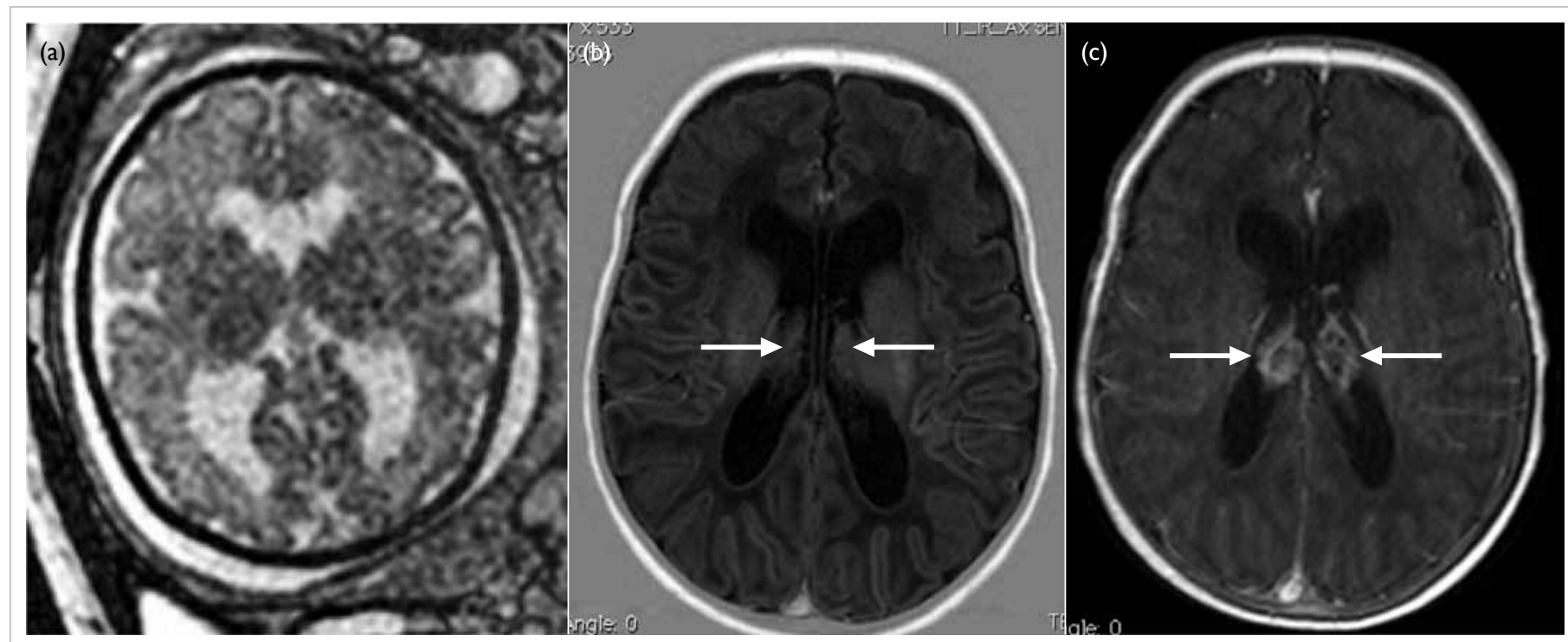

FIG I. A fetus with a history of borderline ventriculomegaly and suspected partial agenesis of corpus callosum on antenatal ultrasound at 35 gestational weeks

(a) An axial T2 image performed at 35 gestational weeks showing mild ventriculomegaly. There is no evidence of agenesis of corpus callosum. Neonatal magnetic resonance imaging performed at I month of age: (b) TI inversion recovery sequence showing persistent mild ventriculomegaly with prominence of choroid plexuses (arrows), and (c) TI-weighted sequence with gadolinium revealing diffuse enhancement of the choroid plexuses (arrows); overall findings suggest diffuse villous hyperplasia of choroid plexus

on parental counselling and perinatal management.

\section{Corpus callosum abnormalities}

The corpus callosum is the main commissural pathway in the brain and comprises the rostrum, genu, body, and splenium. Beginning at 8 weeks of gestation, it develops from the lamina of His, with an apparent anteroposterior progression, starting from the genu, progressing posteriorly to the body and splenium, followed by the rostrum. By 15 to 20 weeks, the corpus callosum has assumed its final shape with fusion of all of its parts. ${ }^{6}$ Thus caution should be exercised when evaluating the corpus callosum before 20 weeks.

Abnormalities of the corpus callosum include agenesis, hypogenesis, dysgenesis, hypoplasia, and destruction. The precise incidence of corpus callosum abnormalities is difficult to ascertain because of selection bias in reported series. In a large population-based study looking at data from the California Birth Defect Monitoring Program, ${ }^{41}$ the authors identified 630 (0.019\%) cases of agenesis or hypoplasia of the corpus callosum in 3.4 million live births. While agenesis of the corpus callosum can sometimes be seen in asymptomatic individuals, most patients exhibit variable neurological symptoms, including developmental delay, cognitive impairment, and epilepsy. There is also a high association with other CNS abnormalities such as sulcation abnormalities, Dandy-Walker malformation, Chiari II malformation, and grey matter heterotopia. ${ }^{3,6,9}$

On sonography, the corpus callosum is best visualised and evaluated on the mid-sagittal image, but obtaining an optimal mid-sagittal view can be challenging, especially at an advanced gestational age. We often rely on indirect signs including absence of cavum septum pellucidum, colpocephaly, high-riding third ventricle, and radiating gyri.,

Fetal MR imaging overcomes these challenges with its multiplanar capabilities and is able to demonstrate the corpus callosum in its entire length on the mid-sagittal image as a curvilinear C-shaped T2 hypointense structure at the superior margin of the cavum septum pellucidum and lateral ventricles. $^{3}$ The indirect signs of callosal agenesis, similar to those on sonography, can also be depicted on the axial and coronal images ${ }^{3,6}$ (Fig 2). Studies have shown a higher sensitivity and specificity with fetal MR imaging compared with sonography. ${ }^{38,42}$

The prognosis of corpus callosum abnormalities is highly variable, depending not on the callosal abnormality itself, but largely on the associated abnormalities in the CNS and other systems, and have been found to be as common as $85 \%$ on autopsy. ${ }^{5}$ Fetal MR imaging has been shown to demonstrate additional but sonographically occult anomalies in up to $93 \%$ of cases of callosal abnormalities. ${ }^{5,9}$ Accurate detection of associated abnormalities has an important implication on the prognostication of the current pregnancy and the recurrence risk in future pregnancies. ${ }^{3,5}$ 


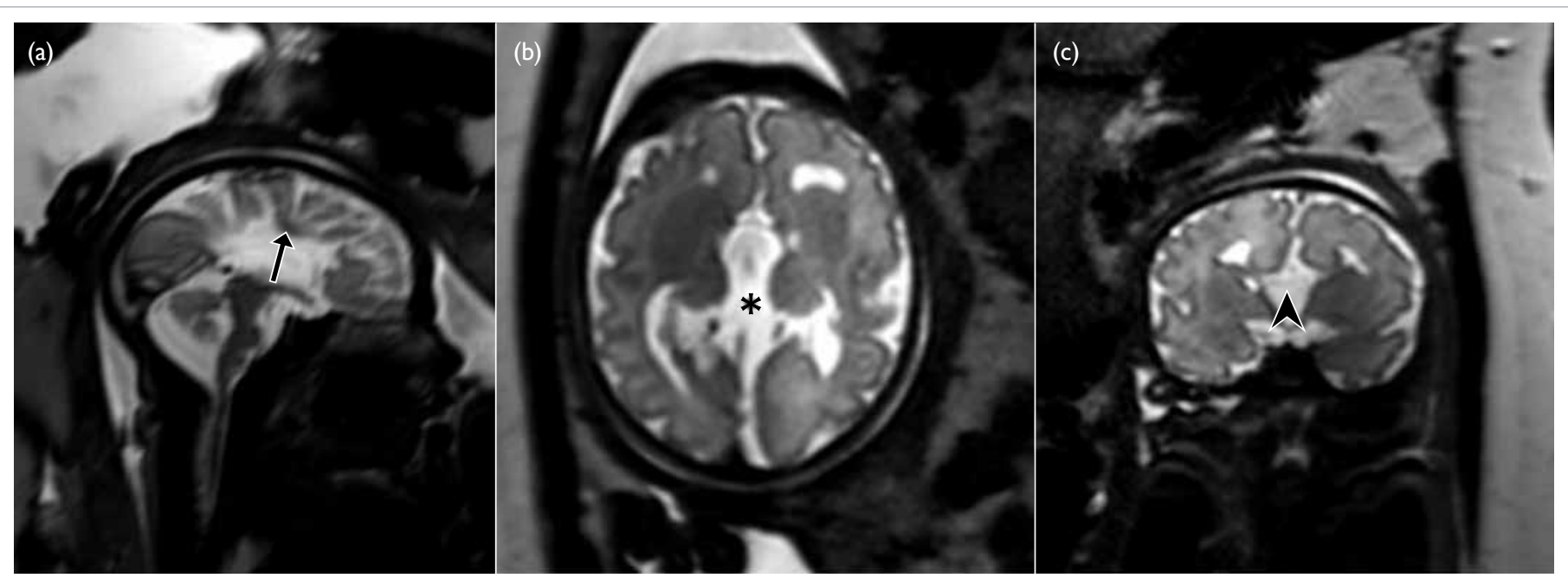

FIG 2. A fetus of 35 gestational weeks

(a) Midline sagittal T2, (b) coronal T2, and (c) axial T2 images demonstrating agenesis of corpus callosum, as evidenced by radiating gyri (arrow), absence of cavum septum pellucidum (asterisk), colpocephaly and high-riding third ventricle (arrowhead)

\section{Complications of monochorionic twin pregnancies}

While fetal MR imaging is commonly used for further evaluation of suspected sonographic abnormalities, there has been an increasing clinical use in the screening of high-risk cases. ${ }^{3,31,43}$ Fetal MR imaging is particularly useful in monochorionic twin pregnancies complicated by twin-twin transfusion syndrome or co-twin fetal demise where sonography of the brain is unrevealing. ${ }^{43,44}$

In twin-twin transfusion syndrome, there is imbalanced blood flow from the smaller donor twin to the larger recipient twin via abnormal intertwin vascular connections in the shared common monochorionic placenta. The donor twin develops oliguria and oligohydramnios from volume depletion, while the recipient twin develops polyuria and polyhydramnios from volume overload. High morbidity and mortality are observed, with both donor and recipient twins at a higher risk of cerebral ischaemia and haemorrhage, and neurodevelopmental and sonographic abnormalities. ${ }^{3,44}$ Although imaging the oligohydramniotic twin is usually straightforward, imaging the polyhydramniotic twin can be difficult owing to excessive fetal motion.

In co-twin fetal demise, an increased risk of neurological impairment is seen in the surviving co-twin (Fig 3). The likely mechanisms of cerebral injury are believed to involve an acute haemodynamic disturbance due to exsanguination of the surviving co-twin into the dead fetus just before or at the time of fetal demise, as well as thromboembolic events at the time of demise. ${ }^{3,43}$

Because of the high morbidity in these twin pregnancy complications, fetal MR imaging can be employed to look for cerebral injuries even when sonography appears normal, such as periventricular leukomalacia, encephalomalacia, germinal matrix haemorrhage, intra-ventricular haemorrhage, intraparenchymal haemorrhage, and cortical malformations. It has been found that one third of the surviving twins of co-twin fetal demise had abnormal cerebral findings on fetal MR imaging; most of which were occult sonographically. ${ }^{41}$ In addition, early manifestations of cerebral ischaemia were better diagnosed with MR imaging than sonography, especially DWI.,3,3

\section{Posterior cranial fossa abnormalities}

Fetal MR imaging is useful in evaluating the posterior cranial fossa, utilising its ability to directly visualise the cerebellar hemisphere, vermis, and brainstem in three orthogonal planes, providing global assessment of the posterior fossa structures with morphologic and biometric analysis. It is also used to evaluate for supratentorial abnormalities that are commonly associated with various posterior fossa diseases, and can aid diagnosis and prognostication. Posterior fossa abnormalities that can be evaluated by fetal MR imaging include Dandy-Walker spectrum, cerebellar hypoplasia, cerebellar dysplasia, cerebellar haemorrhage, and Chiari malformation..$^{5,6,9,45}$

Dandy-Walker malformation is characterised by agenesis or hypoplasia of the cerebellar vermis, in association with an enlarged posterior fossa, torcular-lambdoid inversion, and cystic dilatation of the fourth ventricle. ${ }^{5,6,9}$ While severe cases of DandyWalker malformation can be readily identified by sonography, distinguishing milder forms of 


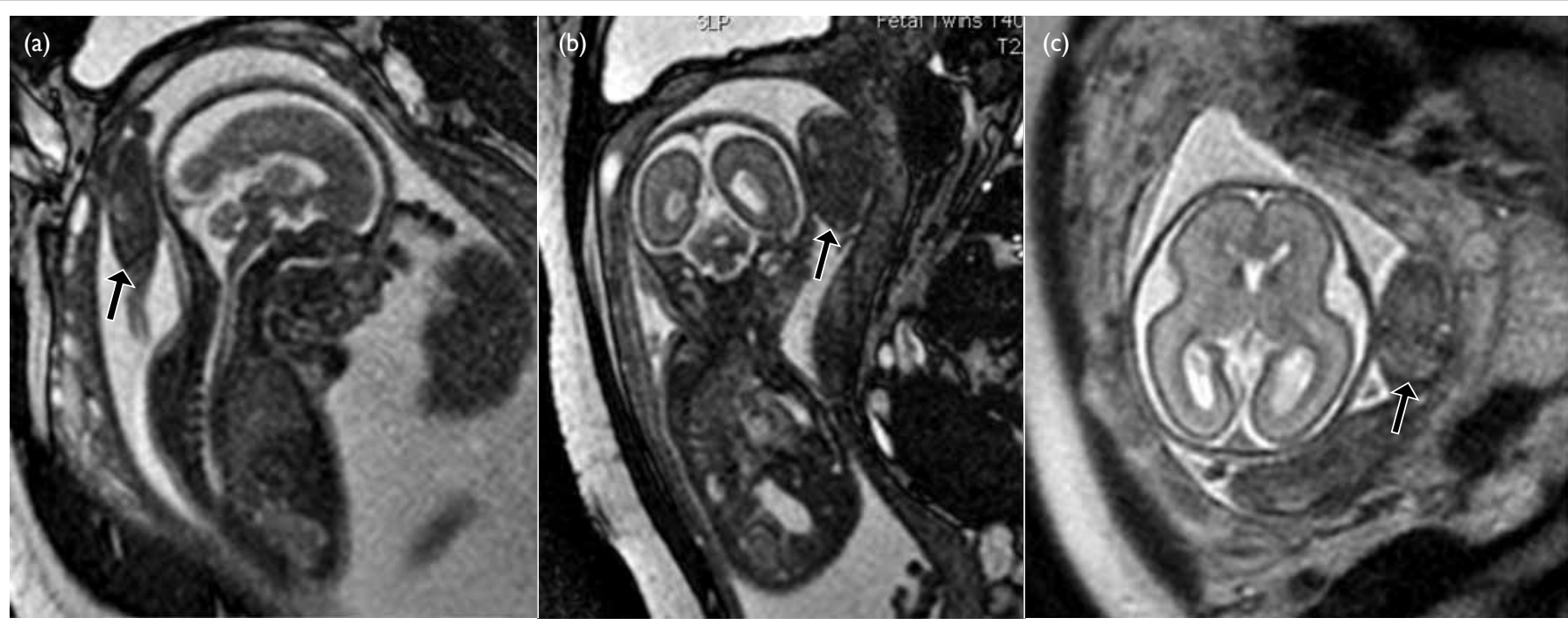

FIG 3. A 23-week gestation fetus with co-twin demise

(a) Sagittal T2, (b) coronal T2, and (c) axial T2 images showing small demised twin (arrows) and surviving twin with normal intracranial appearance

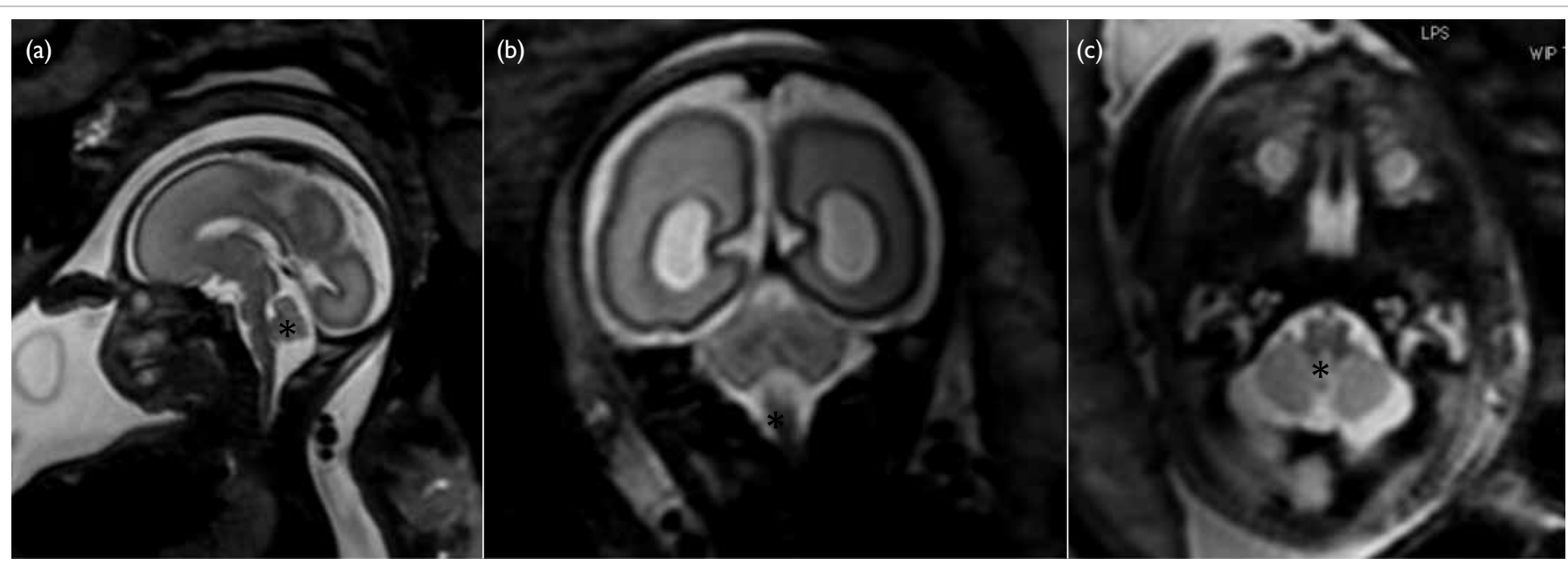

FIG 4. A 23-week gestation fetus with a history of enlarged retrocerebellar space on ultrasound

(a) Sagittal midline T2, (b) coronalT2, and (c) axialT2 images confirm that although the transverse diameter of the cerebellum is marginally small for gestational age, the cerebellar vermis (asterisks) was intact

vermian hypoplasia from a mega cisterna magna or an arachnoid cyst can be challenging (Figs 4 and 5). This is even more difficult in the third trimester where ossification of the skull can limit sonographic assessment of the posterior fossa structures. With its multiplanar capabilities, fetal MR imaging can better evaluate the morphology of the vermis, as well as the anatomical relationship between a retrocerebellar cyst and the fourth ventricle, which can help differentiate a Dandy-Walker variant from other entities such as a mega cisterna magna., ${ }^{5,25}$ In addition, fetal MR imaging is able to evaluate the supratentorial structures, because the Dandy-Walker spectrum is also associated with supratentorial abnormalities such as agenesis of corpus callosum, polymicrogyria, neuronal heterotopia, and occipital encephalocele, ${ }^{5}$ and is associated with a poorer clinical outcome. On the other hand, radiologists should also be aware of the limitations of fetal MR imaging. At younger gestational age (such as $<20$ weeks), fetal MR imaging may have a reduced specificity, particularly in the diagnosis of isolated inferior vermian hypoplasia., ${ }^{5,9}$ This may be related to small size, fetal motion, volume averaging, and 


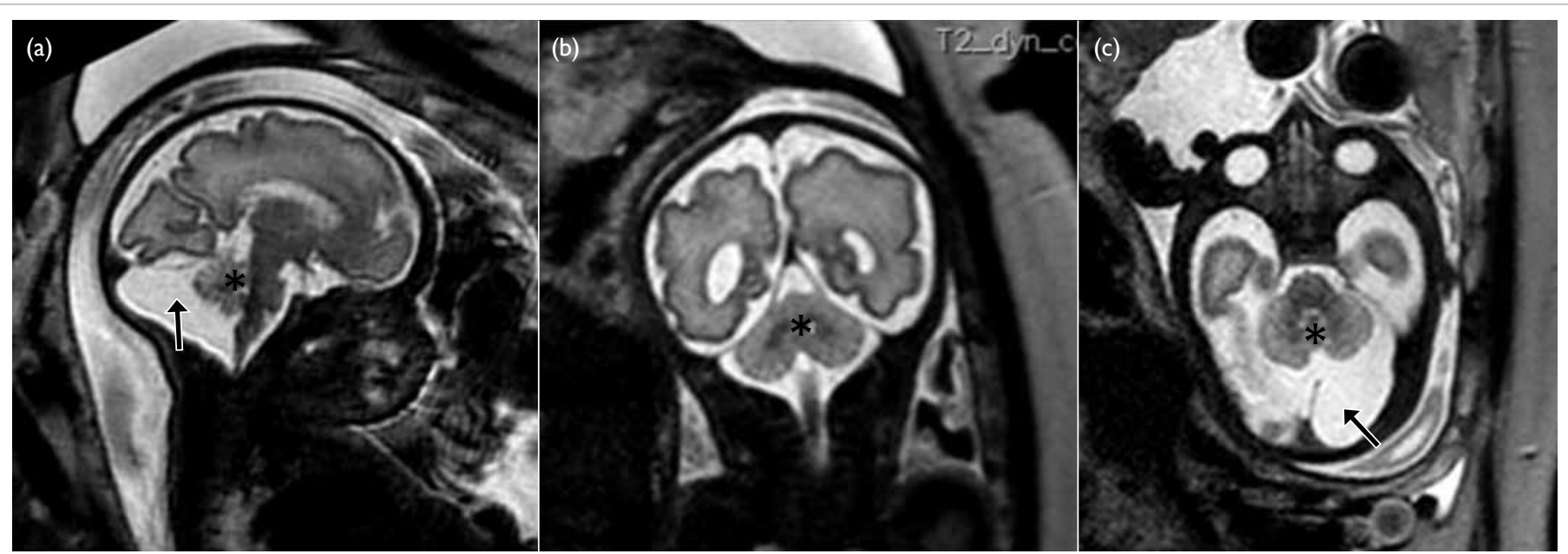

FIG 5. A 32-week gestation fetus: antenatal ultrasonography showing enlarged retrocerebellar space

(a) Sagittal T2 images at midline, (b) coronal T2 image, and (c) sagittal T2 image depicting an intact cerebellar vermis (asterisks) and a mega cisterna magna (arrows)

difficulty in obtaining a true mid-sagittal image. Follow-up MR imaging, either at a later gestational age or postnatally, is recommended in such cases. ${ }^{46}$

The cerebellar hemispheres can be evaluated on fetal MR imaging by assessing their size and morphology in multiple planes, in which normative data have been published for different gestational ages. ${ }^{3}$ Furthermore, DWI can provide quantitative information on the developing cerebellum that normally demonstrates a progressive decline in diffusivity and apparent diffusion coefficient values with increasing gestational age.

Fetal MR imaging is also helpful in evaluating echogenic posterior fossa masses. Haemorrhage is typically hyperintense on T1-weighted images, hypointense on T2-weighted images, with susceptibility artefact on gradient echo T2* images, although the signal intensity can vary depending on the age of the haemorrhage. In addition to confirming the diagnosis, fetal MR imaging can also better delineate the location of the haemorrhage, whether it is intra-axial or extra-axial which have different pathophysiology. The underlying causes of the cerebellar haemorrhage can be evaluated on MR imaging, such as germinal matrix haemorrhages, vascular malformations, and congenital infections. ${ }^{38}$

\section{Conclusions}

Magnetic resonance imaging is a safe and powerful adjunct to sonography in prenatal evaluation of the fetal brain. Facilitated by recent technological advancements, fetal MR imaging is being increasingly used in the clinical evaluation of cerebral abnormalities and screening of high-risk fetuses. It can provide additional useful information that can alter clinical management and aid in prognostication and counselling. Radiologists and clinicians involved in prenatal imaging and management should be aware of the application and limitations of the modalities available in fetal imaging, so as to optimise the multidisciplinary care for our patients.

\section{Acknowledgement}

The authors thank Professor Mary Rutherford, Centre for the Developing Brain, Perinatal Imaging \& Health Imaging Sciences \& Biomedical Engineering Division, King's College London, St Thomas' Hospital, London, United Kingdom.

\section{References}

1. Blondiaux E, Sileo C, Nahama-Allouche C, et al. Periventricular nodular heterotopia on prenatal ultrasound and magnetic resonance imaging. Ultrasound Obstet Gynecol 2013;42:149-55.

2. Blondiaux E, Garel C. Fetal cerebral imaging-ultrasound vs. MRI: an update. Acta Radiol 2013;54:1046-54.

3. Glenn OA. MR imaging of the fetal brain. Pediatr Radiol 2010;40:68-81.

4. Mirsky DM, Shekdar KV, Bilaniuk LT. Fetal MRI: head and neck. Magn Reson Imaging Clin N Am 2012;20:605-18.

5. Kline-Fath BM, Calvo-Garcia MA. Prenatal imaging of congenital malformations of the brain. Semin Ultrasound CT MR 2011;32:167-88.

6. Saleem SN. Fetal magnetic resonance imaging (MRI): a tool for a better understanding of normal and abnormal brain development. J Child Neurol 2013;28:890-908.

7. Bulas D, Egloff A. Benefits and risks of MRI in pregnancy. Semin Perinatol 2013;37:301-4.

8. Mailath-Pokorny M, Kasprian G, Mitter C, Schöpf V, Nemec U, Prayer D. Magnetic resonance methods in fetal neurology. Semin Fetal Neonatal Med 2012;17:278-84. 
9. O'Connor SC, Rooks VJ, Smith AB. Magnetic resonance imaging of the fetal central nervous system, head, neck, and chest. Semin Ultrasound CT MR 2012;33:86-101.

10. International Commission on Non-Ionizing Radiation Protection. Medical magnetic resonance (MR) procedures: protection of patients. Health Phys 2004;87:197-216.

11. Health and Safety Executive. Non-auditory effects of noise at work: a critical review of the literature. Sudbury: HSE Books; 1999.

12. Noise: a hazard for the fetus and newborn. American Academy of Pediatrics. Committee on Environmental Health. Pediatrics 1997;100:724-7.

13. Glover P, Hykin J, Gowland P, Wright J, Johnson I, Mansfield P. An assessment of the intrauterine sound intensity level during obstetric echo-planar magnetic resonance imaging. Br J Radiol 1995;68:1090-4.

14. Expert Panel on MR Safety, Kanal E, Barkovich AJ, Bell C, et al. ACR guidance document on MR safe practices: 2013. J Magn Reson Imaging 2013;37:501-30.

15. Williams F, Griffiths PD. The diagnosis of hemimegalencephaly using in utero MRI. Clin Radiol 2014;69:e291-7.

16. Griffiths PD, Jarvis D, McQuillan H, Williams F, Paley M, Armitage P. MRI of the foetal brain using a rapid 3D steady-state sequence. Br J Radiol 2013;86:20130168.

17. Malamateniou C, Malik SJ, Counsell SJ, et al. Motioncompensation techniques in neonatal and fetal $M R$ imaging. AJNR Am J Neuroradiol 2013;34:1124-36.

18. Glenn OA, Cuneo AA, Barkovich AJ, Hashemi Z, Bartha AI, $\mathrm{Xu}$ D. Malformations of cortical development: diagnostic accuracy of fetal MR imaging. Radiology 2012;263:843-55.

19. Shekdar K, Feygin T. Fetal neuroimaging. Neuroimaging Clin N Am 2011;21:677-703, ix

20. Clouchoux C, Limperopoulos C. Novel applications of quantitative MRI for the fetal brain. Pediatr Radiol 2012;42 Suppl 1:S24-32.

21. Mignone Philpott C, Shannon P, Chitayat D, Ryan G, Raybaud CA, Blaser SI. Diffusion-weighted imaging of the cerebellum in the fetus with Chiari II malformation. AJNR Am J Neuroradiol 2013;34:1656-60.

22. Kasprian G, Del Río M, Prayer D. Fetal diffusion imaging: pearls and solutions. Top Magn Reson Imaging 2010;21:387-94.

23. StoryL,Damodaram MS,Supramaniam V,etal.Myo-inositol metabolism in appropriately grown and growth-restricted fetuses: a proton magnetic resonance spectroscopy study. Eur J Obstet Gynecol Reprod Biol 2013;170:77-81.

24. Vasung L, Fischi-Gomez E, Huppi PS. Multimodality evaluation of the pediatric brain: DTI and its competitors. Pediatr Radiol 2013;43:60-8

25. Girard NJ. Magnetic resonance imaging of fetal developmental anomalies. Top Magn Reson Imaging 2011;22:11-23.

26. Huisman TA. Fetal magnetic resonance imaging of the brain: is ventriculomegaly the tip of the syndromal iceberg? Semin Ultrasound CT MR 2011;32:491-509.

27. Story L, Damodaram MS, Allsop JM, et al. Brain metabolism in fetal intrauterine growth restriction: a proton magnetic resonance spectroscopy study. Am J Obstet Gynecol 2011;205:483.e1-8.

28. Meoded A, Poretti A, Tekes A, Flammang A, Pryde S, Huisman TA. Prenatal MR diffusion tractography in a fetus with complete corpus callosum agenesis. Neuropediatrics
2011;42:122-3.

29. Schöpf V, Kasprian G, Prayer D. Functional imaging in the fetus. Top Magn Reson Imaging 2011;22:113-8.

30. Story L, Damodaram MS, Allsop JM, et al. Proton magnetic resonance spectroscopy in the fetus. Eur J Obstet Gynecol Reprod Biol 2011;158:3-8.

31. Griffiths PD, Porteous M, Mason G, et al. The use of in utero MRI to supplement ultrasound in the foetus at high risk of developmental brain or spine abnormality. Br J Radiol 2012;85:e1038-45.

32. Doneda C, Parazzini C, Righini A, et al. Early cerebral lesions in cytomegalovirus infection: prenatal MR imaging. Radiology 2010;255:613-21.

33. Lipitz S, Hoffmann C, Feldman B, Tepperberg-Dikawa M, Schiff E, Weisz B. Value of prenatal ultrasound and magnetic resonance imaging in assessment of congenital primary cytomegalovirus infection. Ultrasound Obstet Gynecol 2010;36:709-17.

34. Griffiths PD, Reeves MJ, Morris JE, et al. A prospective study of fetuses with isolated ventriculomegaly investigated by antenatal sonography and in utero MR imaging. AJNR Am J Neuroradiol 2010;31:106-11.

35. Dhouib A, Blondiaux E, Moutard ML, et al. Correlation between pre- and postnatal cerebral magnetic resonance imaging. Ultrasound Obstet Gynecol 2011;38:170-8.

36. Griffiths PD, Morris JE, Mason G, et al. Fetuses with ventriculomegaly diagnosed in the second trimester of pregnancy by in utero MR imaging: what happens in the third trimester? AJNR Am J Neuroradiol 2011;32:474-80.

37. Mehrabi S, Adami A, Ventriglia A, Zantedeschi L, Franchi M, Manfredi R. Evolution of ventriculomegaly: comparison between foetal MR imaging and postnatal diagnostic imaging. Radiol Med 2013;118:1199-211.

38. Manganaro L, Bernardo S, La Barbera L, et al. Role of foetal MRI in the evaluation of ischaemic-haemorrhagic lesions of the foetal brain. J Perinat Med 2012;40:419-26.

39. Manfredi R, Tognolini A, Bruno C, Raffaelli R, Franchi M, Pozzi Mucelli R. Agenesis of the corpus callosum in fetuses with mild ventriculomegaly: role of MR imaging. Radiol Med 2010;115:301-12.

40. Yin S, Na Q, Chen J, Li-Ling J, Liu C. Contribution of MRI to detect further anomalies in fetal ventriculomegaly. Fetal Diagn Ther 2010;27:20-4

41. Glass HC, Shaw GM, Ma C, Sherr EH. Agenesis of the corpus callosum in California 1983-2003: a populationbased study. Am J Med Genet A 2008;146A:2495-500.

42. Griffiths PD, Russell SA, Mason G, Morris J, Fanou E, Reeves MJ. The use of in utero MR imaging to delineate developmental brain abnormalities in multifetal pregnancies. AJNR Am J Neuroradiol 2012;33:359-65.

43. Hoffmann C, Weisz B, Yinon Y, et al. Diffusion MRI findings in monochorionic twin pregnancies after intrauterine fetal death. AJNR Am J Neuroradiol 2013;34:212-6.

44. Tarui T, Khwaja OS, Estroff JA, Robinson JN, Gregas MC, Grant PE. Altered fetal cerebral and cerebellar development in twin-twin transfusion syndrome. AJNR Am J Neuroradiol 2012;33:1121-6.

45. Righini A, Parazzini C, Doneda C, et al. Fetal MRI features related to the Chiari malformations. Neurol Sci 2011;32 Suppl 3:S279-81.

46. Guibaud L, Larroque A, Ville D, et al. Prenatal diagnosis of 'isolated' Dandy-Walker malformation: imaging findings and prenatal counselling. Prenat Diagn 2012;32:185-93. 